\title{
Morphological Studies on the Adrenal Gland of Kuttanad Ducks (Anas platyrhynchos domesticus) During Post Hatch Period
}

\author{
*Fathima, R. ${ }^{1}$ and K. M. Lucy ${ }^{2}$ \\ Department of Veterinary Anatomy and Histology, \\ College of Veterinary and Animal Sciences, Mannuthy- 680651, Kerala, India.
}

\begin{abstract}
Post hatch development of adrenal gland in Kuttanad ducks was studied using 78 female birds ranging from day-old to 24 weeks of age. Adrenal glands were collected from six birds in each age group at fortnightly intervals. The glands were too small in the day-old ducklings and were located in the body cavity ventral to the anterior pole of cephalic lobe of kidney just posterior to the lungs. The left adrenal was closely related to the ovary in all the age groups and was deeply embedded in the ovary occasionally. In day-old ducklings, both the glands were globular in shape but later the right adrenal became roughly pyramidal with the apex pointing caudally, while the left one was elongated and flattened dorsoventrally. The glands were cream or yellow in colour in younger birds, but later the colour changed to brown. The left adrenal gland was slightly heavier than the right in all the age groups. The mean weight of the gland increased progressively from day-old to 12 weeks of age and thereafter it showed an irregular pattern up to sexual maturity. The absolute mean adrenal weight in Kuttanad duck was $6.27 \mathrm{mg}$ per $100 \mathrm{~g}$ body weight at 12th week of age and reached a level of $5.31 \mathrm{mg}$ at 16th week (at the beginning of egg laying) and again increased to $9.60 \mathrm{mg}$ per $100 \mathrm{~g}$ body weight at 24 weeks of age. The combined adrenal weight was more correlated with the age than with the body weight. The proportionate mean weight of the adrenal glands to the body weight showed a decreasing trend during post hatch period.
\end{abstract}

Key words: Morphology, Adrenal glands, Kuttanad ducks, Post hatch period

\section{Introduction}

The adrenal gland is an important endocrine organ performing the vital functions of an organism. It produces multiple hormones and regulates several physiological functions. Completely adrenalectomized birds will die within 60 hours, which depicts the importance of these glands. Although extensive research has been conducted on the adrenal gland of domestic fowl and Japanese quail, information regarding the normal structure and post hatch development of the adrenal gland in duck is scanty. Kuttanad ducks are reared extensively in Kerala and are well adapted to the climatic conditions of the state. Therefore, comprehensive study on the developmental pattern of the adrenal gland in this species seems to be a relevant area of research.

\section{Materials And Methods}

The present study was conducted on the adrenal gland of 78 Kuttanad ducks. They were selected randomly from a single hatch and reared at the University Poultry and Duck Farm, Mannuthy under semiintensive system of management. The study was carried out in female birds of different age groups, ranging from day-old to 24 weeks. The materials were collected from six birds in each age group at fortnightly intervals. After recording the body weight, the birds were humanely sacrificed and morphological studies were carried out.

\section{Topography}

\section{Results And Discussion}

The paired adrenal glands in day-old Kuttanad ducklings were very small and located in the body cavity ventral to the anterior pole of cephalic lobe of kidney just posterior to the lungs, as reported by [1], [2] and [3] in chicken. Both the glands were very close in position and were separated by a small amount of connective tissue in younger age groups, but as the age advanced they showed a better degree of separation.

The gonads were situated on the ventral surface of the adrenal glands. The left adrenal was closely related to the dorsal surface of the ovary in all the age groups and occasionally, the left one was deeply embedded in it. In the hen, the left gland was embedded within the ovarian stalk [4].

\section{Shape and Colour}

In day-old ducklings, both the glands were globular in shape. As age advanced, the glands became dissimilar in form and shape. The right adrenal was roughly pyramidal with the apex pointing caudally, while the left one was elongated and flattened dorsoventrally (Fig. 1), as reported in domestic fowl [2] and in ostrich chick [5]. The adrenal showed external lobulation (Fig. 2) which was evident especially in older age groups as 
reported in ostrich [5] and in adult chicken [3]. Compared to the right gland, the left one exhibited more variation in shape. Even within the age group, individual variations were visible in the shape of the glands. [6] opined that it was very difficult to make any generalization regarding the shape of adrenals even within the species.

The adrenal glands were cream or yellow in colour in younger age groups, but later, the colour became brown. The carotenoids present in the lipid droplet imparted yellow colour to the gland [7]. Slight degree of individual variation was also evident in the colour of adrenals between the birds of same age groupin fowl [6].

\section{Relationship between Age and Body Weight}

Body weight and age of birds used for the study are given in table 1 . The mean body weight of the dayold duckling was $35.60 \pm 1.32 \mathrm{~g}$. Body weight of the birds increased rapidly up to eight weeks of age followed by a gradual growth up to 16 weeks at which the maximum mean body weight of $1658.33 \pm 27.25 \mathrm{~g}$ was attained and the birds started laying eggs. The body weight increased 37 times by eight weeks and 47 times by 18 weeks from the day of hatch. From $18^{\text {th }}$ week onwards, the body weight showed a decreasing trend and at $24^{\text {th }}$ week of age, the mean body weight was $1426.67 \pm 35.65 \mathrm{~g}$. The reason for this progressive increase in body weight followed by a phase of rapid decrease might be the heavy deposition of lipids in pre-laying period followed by utilization of this stored lipids during laying period for the formation of eggs as observed in common mallard [8] and in migratory Ruddy ducks [9]. Body weight exhibited highly significant correlation with the age during post hatch period (Table 2).

\section{Weight of Adrenal Glands}

Weight of adrenal gland at different ages is given in table 1 . The left adrenal gland was slightly heavier than the right in all the age groups (Fig. 3) in chicken [3]. The mean weight of the gland increased progressively from day-old $(0.011 \pm 0.001 \mathrm{~g})$ to 12 weeks of age $(0.093 \pm 0.002 \mathrm{~g})$ and thereafter it showed an irregular pattern up to sexual maturity. [5] reported that the weight of gland in ostrich chick was $0.45 \pm 0.04 \mathrm{~g}$. It was very difficult to make any generalization since the weight of adrenal glands varied considerably according to species, breed, age, health and various environmental factors in birds [10].

In the present study, a spurt in the mean weight of adrenal gland was noticed from $22^{\text {nd }}(0.091 \pm 0.003$ g) to $24^{\text {th }}$ week of age $(0.137 \pm 0.006 \mathrm{~g})$. [3] reported that in adult chicken, mean weight of the right and left adrenal glands were $97.2 \pm 1.2 \mathrm{mg}$ and $104.1 \pm 1.4 \mathrm{mg}$, respectively. The spurt in weight of adrenal gland from $22^{\text {nd }}$ week to $24^{\text {th }}$ week might be due to the additive effect of sexual activity and summer stress. Female birds were exclusively used for this study and were less able to resist the stress compared to males [11]. The sexually active period in female birds probably caused hypertrophy of the gland due to the effect of estrogen [12]. Estrogen caused the hypertrophy of the adrenal gland while testosterone caused adrenal depression in chicken [13]. The adrenal activity in the Jungle bush quail in India was studied [14] and found that the adrenal weight showed cyclical patterns relative to environmental factors, with maximum value in the active phase of reproduction. Stress of various kinds will increase the size of the adrenals. The adrenal hypertrophy during ovulation and regression following ovulation in the pigeon [15].

The absolute mean adrenal weight in Kuttanad duck was $6.27 \mathrm{mg}$ per $100 \mathrm{~g}$ body weight at $12^{\text {th }}$ week of age and reached a level of $5.31 \mathrm{mg}$ at $16^{\text {th }}$ week (at the beginning of egg laying) and again increased to 9.60 mg per 100 g body weight at 24 weeks of age. The absolute adrenal weight increased with age until 13 weeks that remained almost steady thereafter, in domestic fowl [7]. At 13 weeks of age, weight of adrenal was about 9 mg per $100 \mathrm{~g}$ body weight and reached $6 \mathrm{mg}$ per $100 \mathrm{~g}$ body weight in adult. The variation in the present study might be because of the difference in species and other factors including heavy metabolic demand during egg laying. Weight of the adrenal gland in adult duck was reported to be about $9 \mathrm{mg}$ per $100 \mathrm{~g}$ body weight [16] which is in accordance with the present study. The combined adrenal weight was more correlated with the age than with the body weight. Weight of the adrenal gland in male pigeon was about $5 \mathrm{mg}$ per $100 \mathrm{~g}$ body weight [17] and for the adult duck, it was about $9 \mathrm{mg}$ per $100 \mathrm{~g}$ body weight [16].

The proportionate mean weight of the adrenal glands to the body weight showed a decreasing trend during post hatch period (Table 3). The decrease was significant up to four weeks followed by a marginal increase at $12^{\text {th }}, 20^{\text {th }}$ and $24^{\text {th }}$ weeks. [13] in young fowl and [5] in ostrich reported that the relative weight of adrenals to the body weight was more in younger age groups than in the adults. Slight increase in the proportionate adrenal weight in adult age groups in the present study might be due to the higher activity of the gland during the ovulation. Similar observations were reported in fowl who noticed that in mature female (3234 weeks), the adrenal weighed more than those of the immature (10-11 weeks) and the senile (120-125 weeks) birds [18]. They also reported that absolute adrenal weight was maximum in the adults in both male and female; however it was less in males when compared to the females.

The adrenal size was an indicator of adrenal activity. The marginal increase in relative adrenal weight in 20 to 24 weeks in the present study can be related to the sex of the birds [19]. Here the female birds were used 
for the study and they are thought to be more exposed to social stress than males. More hormones are also needed for the heavy metabolic demand for the preparation of egg laying, yolk deposition, brooding and parental care.

\section{Figures And Tables}

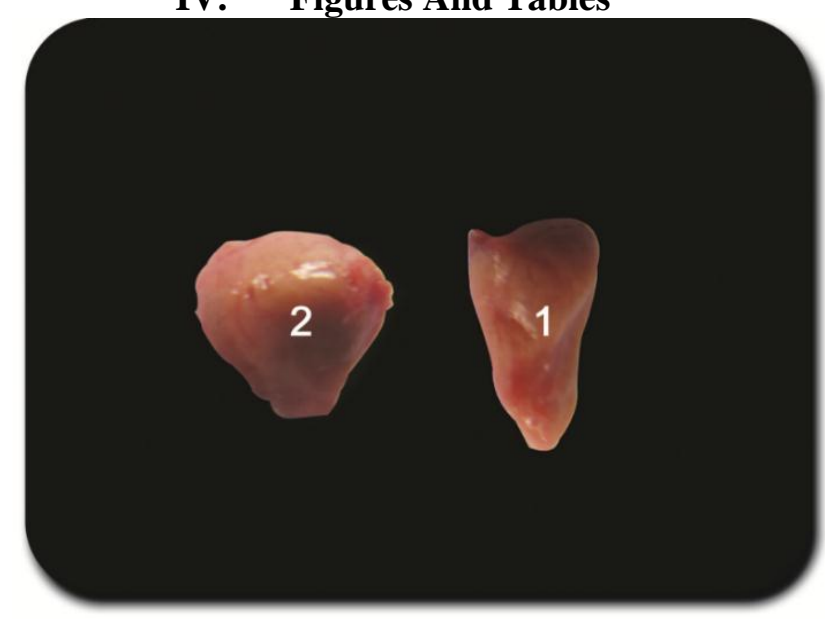

Fig. 1. Adrenal glands (6 weeks)

$\begin{array}{lll}\text { 1. Left adrenal gland } 2 \text {. Right adrenal gland } & \end{array}$

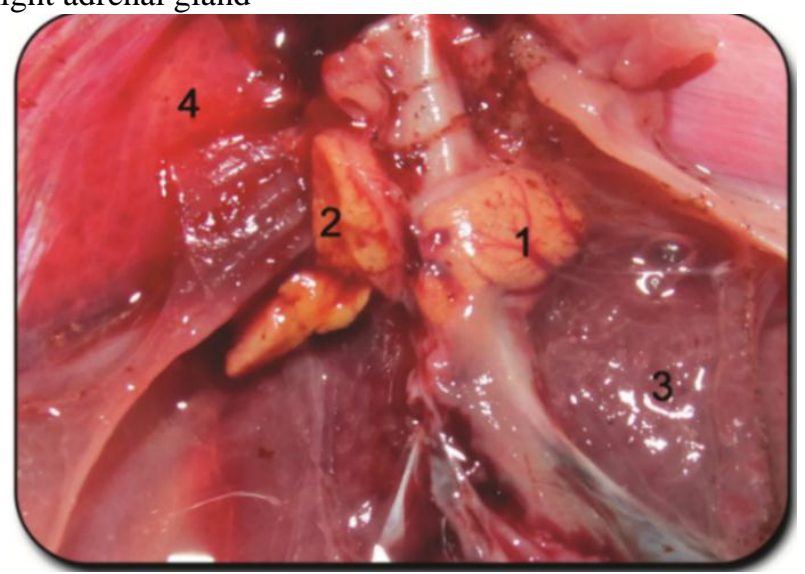

Fig. 2. Right adrenal gland showing external lobulation (10 weeks)

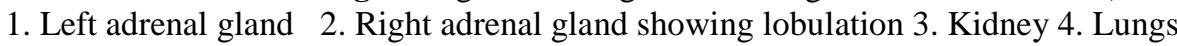

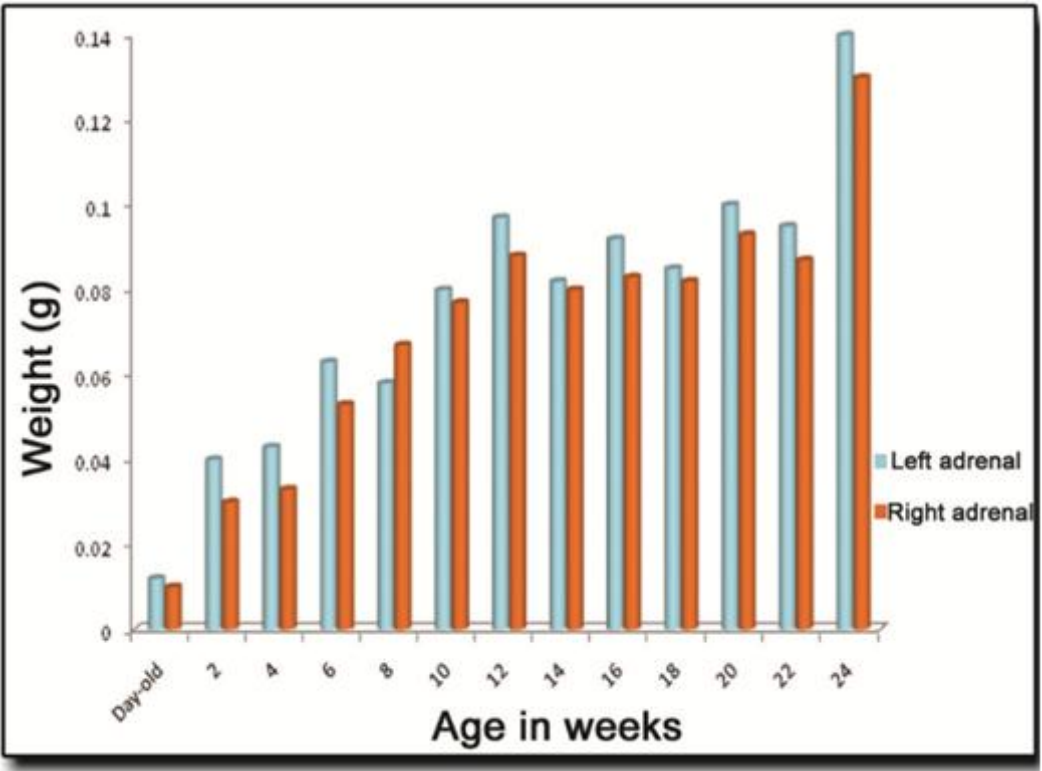

Fig. 3. Comparison of the weight of left and right adrenal glands with age 
Table. 1 Body weight and weight of adrenal gland in Kuttanad ducks at different ages (Mean \pm S.E.)

\begin{tabular}{|l|l|l|l|l|}
\hline \multicolumn{1}{|c|}{ Age } & Body weight $(\mathbf{g})$ & Left adrenal $(\mathbf{g})$ & $\begin{array}{l}\text { Right adrenal } \\
(\mathbf{g})\end{array}$ & $\begin{array}{l}\text { Mean adrenal weight } \\
(\mathbf{g})\end{array}$ \\
\hline Day-old & $35.60 \pm 1.32$ & $0.012 \pm 0.001$ & $0.010 \pm 0.000$ & $0.011 \pm 0.001$ \\
\hline 2 weeks & $241.67 \pm 13.52$ & $0.040 \pm 0.003$ & $0.030 \pm 0.003$ & $0.035 \pm 0.003$ \\
\hline 4 weeks & $626.67 \pm 21.71$ & $0.043 \pm 0.002$ & $0.033 \pm 0.002$ & $0.038 \pm 0.003$ \\
\hline 6weeks & $940.00 \pm 36.51$ & $0.063 \pm 0.006$ & $0.053 \pm 0.004$ & $0.058 \pm 0.002$ \\
\hline 8 weeks & $1306.67 \pm 47.52$ & $0.058 \pm 0.003$ & $0.067 \pm 0.002$ & $0.063 \pm 0.005$ \\
\hline 10 weeks & $1441.67 \pm 14.24$ & $0.080 \pm 0.003$ & $0.077 \pm 0.002$ & $0.079 \pm 0.003$ \\
\hline 12 weeks & $1483.33 \pm 8.03$ & $0.097 \pm 0.003$ & $0.088 \pm 0.002$ & $0.093 \pm 0.002$ \\
\hline 14 weeks & $1543.33 \pm 6.67$ & $0.082 \pm 0.003$ & $0.080 \pm 0.004$ & $0.081 \pm 0.003$ \\
\hline 16 weeks & $1658.33 \pm 27.25$ & $0.092 \pm 0.007$ & $0.083 \pm 0.002$ & $0.088 \pm 0.003$ \\
\hline 18 weeks & $1543.33 \pm 19.61$ & $0.085 \pm 0.002$ & $0.082 \pm 0.005$ & $0.083 \pm 0.003$ \\
\hline 20 weeks & $1535.00 \pm 23.91$ & $0.100 \pm 0.003$ & $0.093 \pm 0.003$ & $0.098 \pm 0.003$ \\
\hline 22 weeks & $1436.67 \pm 20.28$ & $0.095 \pm 0.002$ & $0.087 \pm 0.003$ & $0.091 \pm 0.003$ \\
\hline 24 weeks & $1426.67 \pm 35.65$ & $0.140 \pm 0.007$ & $0.130 \pm 0.007$ & $0.137 \pm 0.006$ \\
\hline
\end{tabular}

Table. 2 Pearson's correlation coefficients (r) of adrenal weight with age and body weight

\begin{tabular}{|l|c|c|}
\hline \multicolumn{1}{|c|}{ Parameters } & Age & Body weight \\
\hline Body weight $(\mathrm{g})$ & $0.818^{* *}$ & - \\
\hline Weight of left adrenal $(\mathrm{g})$ & $0.917^{* *}$ & $0.846^{* *}$ \\
\hline Weight of right adrenal $(\mathrm{g})$ & $0.928^{* *}$ & $0.864^{* *}$ \\
\hline Combined adrenal weight $(\mathrm{g})$ & $0.924^{* *}$ & $0.851^{* *}$ \\
\hline
\end{tabular}

\section{** Correlation is significant at the 0.01 level (2-tailed)}

* Correlation is significant at the 0.05 level (2-tailed)

Table. 3 Proportionatemean weight of adrenal glands to body weight at different ages in Kuttanad ducks

\begin{tabular}{|c|c|}
\hline Age in weeks & Proportionatemean adrenal weight $(\%)$ \\
\hline Day-old & 0.031 \\
\hline 2 & 0.014 \\
\hline 4 & 0.006 \\
\hline 6 & 0.006 \\
\hline 8 & 0.005 \\
\hline 10 & 0.005 \\
\hline 12 & 0.006 \\
\hline 14 & 0.005 \\
\hline 16 & 0.005 \\
\hline 18 & 0.005 \\
\hline 20 & 0.006 \\
\hline 22 & 0.006 \\
\hline 24 & 0.009 \\
\hline
\end{tabular}

\section{Conclusion}

The present study was conducted to understand the morphological changes of adrenal gland of Kuttanad ducks during post hatch period. From this study it was evident that both of the adrenal glands were dissimilar in shape, size and weight. The left adrenal gland was slightly heavier than the right in all the age groups. In day-old ducklings, both the glands were globular in shape. As age advanced, the right adrenal was became roughly pyramidal with the apex pointing caudally, while the left one was elongated and flattened dorsoventrally. The glands were cream or yellow in colour in younger age groups, but later, the colour became brown. Body weight showed a rapid increase up to eight weeks of age followed by a gradual growth up to 16 weeks at which the maximum mean body weight of $1658.33 \pm 27.25 \mathrm{~g}$ was attained.

\section{References}

[1]. Hodges, R. D., The histology of the fowl (Academic Press, London, 1974).

[2]. Nickel, R., Schummer, A. and Seiferle, E. , Anatomy of domestic birds (Verlag Paul Parey, Berlin, 1977). 
[3]. Humayun, K. A. K. M., Aoyama, M. and Sugita, S., Morphological and histological studies on the adrenal gland of the chicken (Gallus domesticus), Journal of Poultry Science, 49, 2012, 39-45.

[4]. Oglesbee, B. L., Orosz. S. and Dorrestein, G. M., The endocrine system, in: R.B. Altman, S .L. Clubb, G. D. Dorrestein and K. Quesenberry (Eds), Avian Medicine and Surgery (W. B. Saunders, Philadelphia, 1997) 475-488

[5]. Tang, L. Peng, K.M., Wang, J. X., Luo, H. Q., Cheng, J. Y., Zhang, G. Y., Sun, Y.F., Liu, H. Z. and Song, H., The morphological study on the adrenal gland of African ostrich chicks, Tissue and Cell,41, 2009, 231-238.

[6]. Hartman, F. A. and Albertin, R. H., A preliminary study of the avian adrenal. The Auk, 68, 1951, $202-209$.

[7]. Ringer, R. K., Adrenals, in P. D. Strukie (Ed.), Avian physiology, 2 (Cornell University Press, New York. 1965) 373-380.

[8]. Krapu, G.L., The role of nutrient reserves in Mallard reproduction. The Auk. 98, 1981, 29-38.

[9]. Tome, M., Changes in nutrient reserves and organ size of female Ruddy ducks breeding in Manitoba, The Auk, 101(4), 1984, 830837.

[10]. Wells, J. W. and Wight, P. A. L, The adrenal glands, in Bell, D. J. and Freeman, B.M. (Eds.), Physiology and biochemistry of domestic fowl, 3 (Academic Press, London, 1971) 489-520.

[11]. Conner, M. H. and Shaffner, C.S., Effect of altered thyroidal and gonadal activity on size of endocrine glands and resistance to stress in chick, Endocrinology, 55, 1954.,45-53.

[12]. Vyas, D. K. and Jacob, D., Seasonal study of the adrenal gland of some Indian avian species, Acta Anatomica, 95, 1976, 518-528.

[13]. Breneman, W. R. The growth of thyroids and adrenals in the chick, Endocrinology, 55(1): 54-64,1954.

[14]. Sudhakumari, C. C., Haldar, C. and Senthilkumaran, B., Seasonal changes in adrenal and gonadal activity in the quail, Perdicula asiatica: involvement of the pineal gland, Comparative Biochemistry and Physiology, 128(4), 2001,793-804.

[15]. Riddle, O., Suprarenal hypertrophy coincident with ovulation. American Journal of Physiology, 66, 1923, $322-339$.

[16]. Boissin, J. Le control hypothalamo-hypophysaire de la function corticosurrenalienne chez le canard. Jouranal of Physiology, (Paris), 59, 1967, 423.

[17]. Bhattacharya, T. K., Sarkar, A. and Ghosh, A., Effect of hydroxylation blocking agents on corticoid concentration in the pigeon adrenals. Endocrinol. Jap, 14, 1967, 265.

[18]. Ganguli, A. and Ahsan, S. N. , Age and sex changes in adrenal weight of common Indian fowl (Gallus domesticus). Indian Veterinary Journal, 65,1988, 783-786.

[19]. Hartman, F. A. and Brownell, K. A. , The adrenal gland (Lea and Febiger, Philadelphia, 1949). 